\title{
The Construction of Beauty in Malay Magazine Advertisements
}

\author{
Weng Marc Lim \\ Monash University \\ E-Mail: lim.weng.marc@monash.edu \\ Ding Hooi Ting \\ Monash University \\ E-Mail: ting.ding.hooi@ monash.edu
}

\begin{abstract}
The images in advertisements have the power to shape one's perception, specifically the way one looks at the world. While the images of women portrayed in most advertisements in the American and European context are often seen as a creation of artificiality that establishes an impossible standard of physical perfection for most women, the question of whether such a state of affairs exists in the Asian context and the underlying reasons for such a state remains in ambiguity. This paper seeks to shed some light in this dark area of the scholarship and contribute its findings to the body of knowledge as it aims to provide an in-depth investigation on how women are portrayed in Malay advertisements and the implications that may be perceived by its viewers, with a concentration on the area of artificiality. Several distinguished famous advertisements featuring women found in Malay magazines that are distributed worldwide were analyzed using a qualitative thematic analysis. The findings of the study indicates that women in Malay advertisements were being portrayed: (i) in an ideal yet artificial state of perfect facial beauty, (ii) passive and as a precious belonging to men, (iii) young with the characteristics of intelligence, cheer and beauty, (iv) being absolutely slim in all conditions, and (v) having high confidence even in their worst periods of the month. The rationales in the elucidation of the observed phenomenon and the subsequent theoretical and managerial implications were also presented in the paper.
\end{abstract}

Keywords: Advertising, Artificiality, Malay, Portrayal, Women 


\section{INTRODUCTION}

Images in advertisements have the power to shape the perception of a society as far as the way they look at the world (Harrison, Biljana and Cornwell, 2001; Kuntjara, 2001). Women, in particular, are often portrayed as sexual objects in advertisements (Berger, 1999; Ford, LaTour and Lundstrom, 1991; Stankiewicz and Rosselli, 2008). Relationally, the conventional beauty is typically a women's main attribute of attraction (Ingham, 1995; Johnston and Taylor, 2008; Ong and Seah, 2001). However, the images of women portrayed in most advertisements are frequently observed as a creation of artificiality that establishes an impossible standard of physical perfection for women (Kuntjara, 2001; Workman and Johnson, 1991). Most studies in the scholarship discusses on the portrayal of women in American and European advertisements (Ferguson, Kreshel and Tinkham, 1990; Heslop, Newman and Gauthier, 2009), particularly those being portrayed as sexual objects (Coleman, 2010; Rhode, 1995; Sengupta, 1992), and its probable meanings to its viewers. However, the area on the implicated meanings that can be derived from the artificiality of women portrayal in advertisements seems to be an infertile area of research, and its understanding in the context of Malay advertisements can be said as null. Hence, there is a need to establish an understanding on how women are portrayed in Malay advertisements and its subsequent implications that viewers may perceive from these advertisements, with a concentration on the area of artificiality. This paper seeks to shed some light on this dark area of research and contribute its findings to the body of knowledge as it aims to provide an in-depth investigation on how women are portrayed in Malay advertisements and the implications that may be perceived by its viewers, with a concentration on the area of artificiality. Relying on the positivist and realist epistemologies, the researchers analyzes the visual materials from the point of view of how images in the materials produce meanings and shared cultural images of woman in Malay magazines among the people and communities via a qualitative thematic analysis.

\section{RESEARCH DESIGN AND METHODOLOGY}

The question of how to make sense of visual materials is closely linked with the question of how to analyze visual materials (Eriksson and Kovalainen, 2008). Observation of existing literature in the scholarship has suggested that meaning-making of the visual is not the same as meaning-making of language (Hooper-Greenhill, 2000; Belova, 2006). The coding and analysis of visual data can be a complicated mater, and figuring out how to relate visual and textual analysis can 
be even more difficult (Eriksson, and Kovalainen, 2008). As such, there is an imperative need to extract data from visual images which are relevant and significant in answering the research question and present them in an organized manner.

\section{Coding}

Coding is an interpretive technique that organizes the data and provide a means to introduce the interpretations of the data into certain qualitative methods (Denzin and Lincoln, 2005; Marshall and Rossman, 1998). According to Lindlof and Taylor (2002), most coding requires researchers to read the data and demarcate segments within it, whereby each segment is labelled with a code, which is usually a word criterion that suggests how the associated data segments inform the research objectives. In the coding of visual images, the visual data are treated and analyzed as a direct representation of reality and as such, the coded visual data are considered as a true and objective state of affairs. Nevertheless, Eriksson and Kovalainen (2008) suggested that there are no specific or rigid rules for the coding and analysis of visual materials. Typically, most researchers are observed to have developed ad hoc coding and analysis solutions for the purpose tailored to their own study (Heath and Hindmarsh, 2002). Hence, the researchers of the current study have developed six major criteria in an attempt to organize the data from the Malay advertisements into an organized manner: 1. The Mood; 2. The Design; 3. The Context and Content; 4. The Signs and Symbols; 5. The Language and Typefaces; and 6. The Themes.

\section{Thematic Analysis}

Five broad themes are developed from the above codes, which are inductive in nature - the researchers are interested in themes for Malay advertisements and extracted them out from the natural variation of the empirical data rather than from any pre-given theoretical framework or any set of pre-formulated propositions. Subsequently, the extracted themes are further discussed with reference with existing literature in the scholarship.

1. Theme of External Beauty (Face). This theme looks at the portrayal pertaining to the importance of a woman's external beauty in terms of the degree of beautifulness of their face. A woman's facial beauty is particularly important as the face is often seen as the main attraction of a woman's conventional beauty (Ingham, 1995; Johnston and Taylor, 2008; Ong and Seah, 2001). As such, the researchers examine how women are portrayed in Malay advertisements in relation to their external facial beauty under this theme. In particular, the 
researchers look to explain the types of problems that a woman may encounter in their attempt to adhere to the ideal beautifulness of the face as portrayed by the women in Malay advertisements. Subsequently, this theme seeks to shed some light on the implications of such portrayed facial problems and how these problems are solved using the example of a woman portrayed using the advertized product. The artificiality of such cure towards the portrayed undesired facial problems of women is also examined.

2. Theme of Intrinsic Beauty (Valued Items). This theme looks at the portrayal pertaining to the importance of a woman's perception of intrinsic beauty in terms of items which are of value to them, in this case, jewelleries. According to Davis, Dionne and Shuster (2001), Moga (2002), Kosher (2006) and Red (2010), jewelleries after often perceived as 'a woman's best friend' as it is viewed by most women as being able to enhance their physical beauty appearance as well as providing a valuable intrinsic meaning if gifted by someone special, usually by their love ones. As such, the researchers examine how women are portrayed in Malay advertisements in relation to their reactions when receiving valued items under this theme. In particular, the researchers look to explain the personality and perception of woman in their encounter of receiving a valued item as a gift from their loved one as portrayed by the women in Malay advertisements. Subsequently, this theme seeks to shed some light on the implications of such portrayed personality and what connotations can be made on such perceptions using the example of a woman portrayed receiving the valued item of the advertized product. The artificiality of such situation occurring towards the portrayed personal choice of valued item is also examined.

3. Theme of Intrinsic Beauty (Personality). This theme looks at the portrayal pertaining to the importance of a woman's intrinsic beauty in terms of personality. According to Kuntjara (2001), the portrayal of women's personality in advertisements may suggest how women in the modern day society should adhere to if they want to have a chance to be wanted. As such, the researchers examine how women are portrayed in Malay advertisements in relation to the different personalities that are deemed to be ideal in the modern day society under this theme. In particular, the researchers look to explain the types of personality that is expected of modern day women as portrayed by women in Malay advertisements. Subsequently, this theme seeks to shed some light on the implications of such portrayed personality and what insinuations can be made of such ideal personalities using the images portraying the actions and ambitions of women in 
Malay advertisements. The possibility of women to have all such personalities is examined on whether such portrayals are of artificial nature.

4. Theme of Confidence. This theme looks at the portrayal pertaining to the importance of a woman's confidence, in this case, during their menstrual period. As mentioned in the previous portfolio, the perception of woman talking about their menstrual periods and sanitary pads is one which is often viewed in a close-minded manner and should not be talked about in public (Ginsburg, 1996; Kay, 2005; Singh, Singh, Arora and Sen, 2006), especially in most prominent Malay conservative-minded countries, like Malaysia (Ong and Seah, 2001) and Indonesia (Frith, Shaw and Cheng, 2005). Nevertheless, there is an increasing trend of sanitary pads being advertized in the local media (Gale, 1993), such as the one presented in this portfolio. As such, the researchers examine how women are portrayed in Malay advertisements in relation to their confidence to come out and participate in such a topic under this theme. In particular, the researchers seek to explain the degree of confidence that a modern day women ought to have as portrayed by women in Malay advertisements. Subsequently, this theme seeks to shed some light on the implications of such portrayed confidence using the images of woman in carrying out demanding activities during such a difficult and challenging period. The possibility of woman to have such high confidence level in a rather difficult period is investigated for artificiality.

5. Theme of External Beauty (Body). This theme looks at the portrayal pertaining to the importance of a woman's external beauty in terms of the ideal body shape. According to Chu (2010) and Chan (2010), modern day woman highly regard the conforming of their body shape to one that is ideal in the modern day society very seriously. Cash and Diane (1982), Chakraborty (2009) and Venkat (2009) supports the former findings as it was also found that there is a demand for body beautifying services as seen by the mushrooming of body beautifying centres. As such, the researchers examine how women are portrayed in Malay advertisements in relation to how the ideal body shape is perceived under this theme. In particular, the researchers seek to explain the type of body shape that modern day women ought to have as portrayed by women in Malay advertisements. Subsequently, this theme seeks to shed some light on the implications of such portrayed body shape using the images of women with their full body figures. The artificiality of such body figures that modern day women ought to have is also examined. 


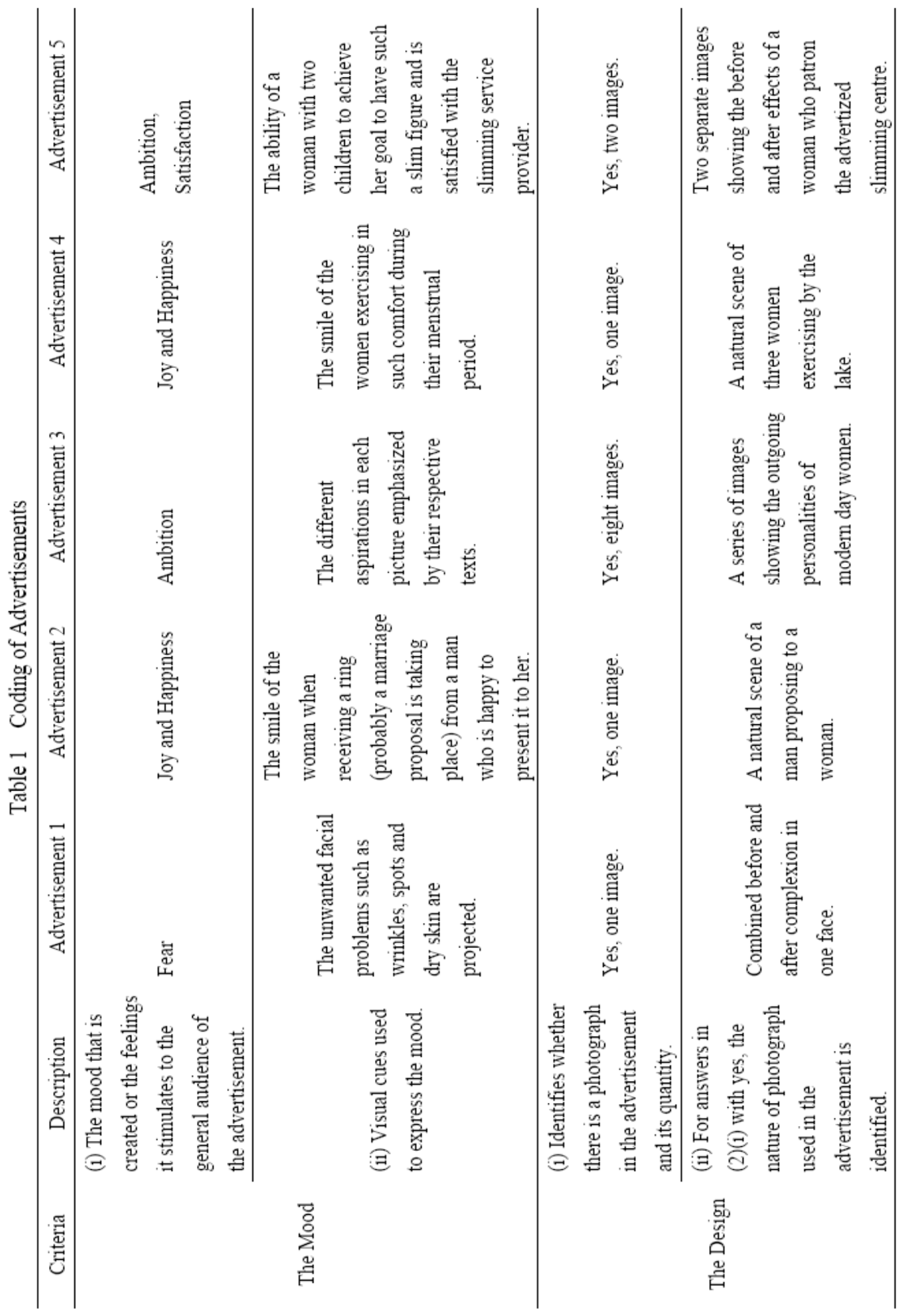




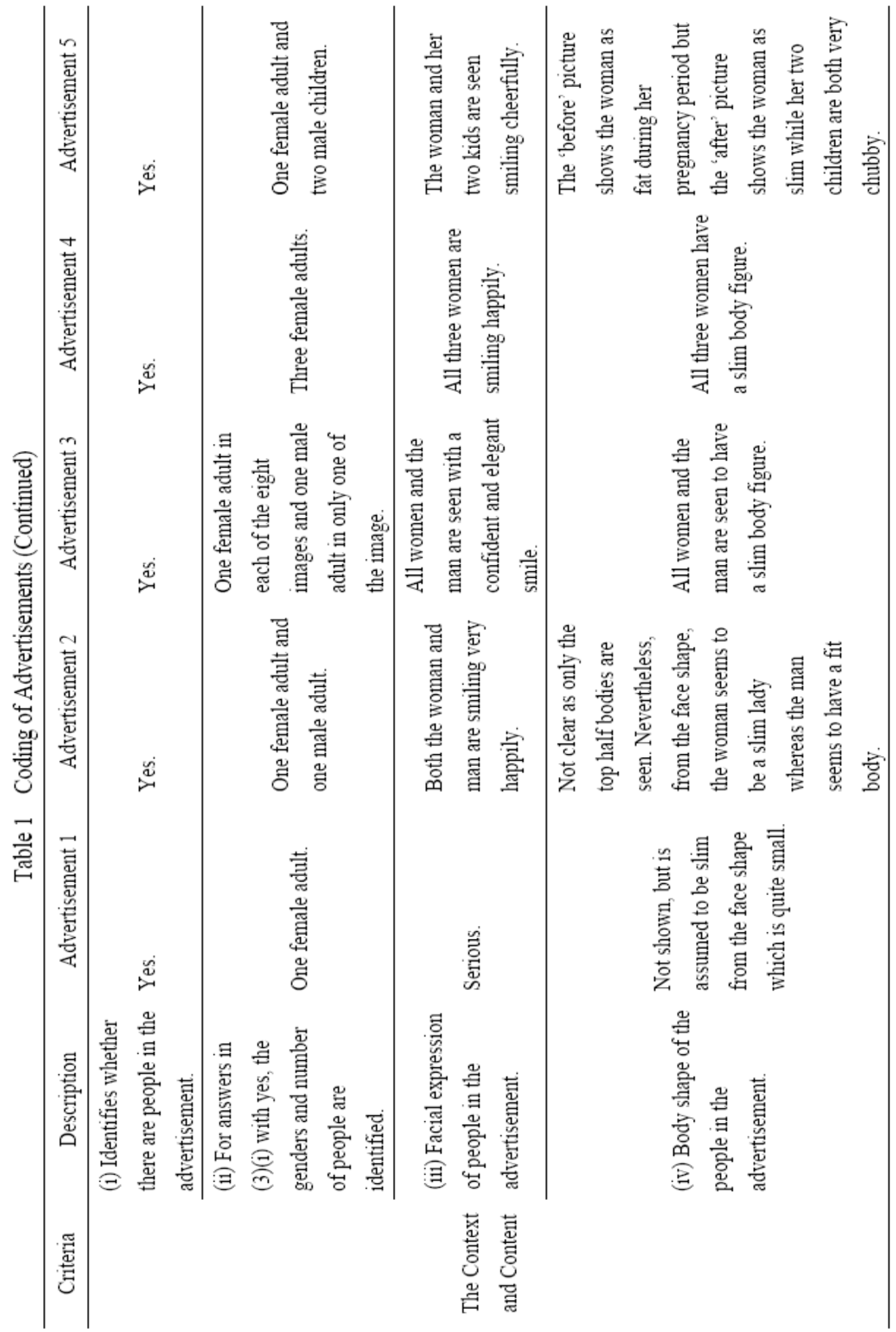




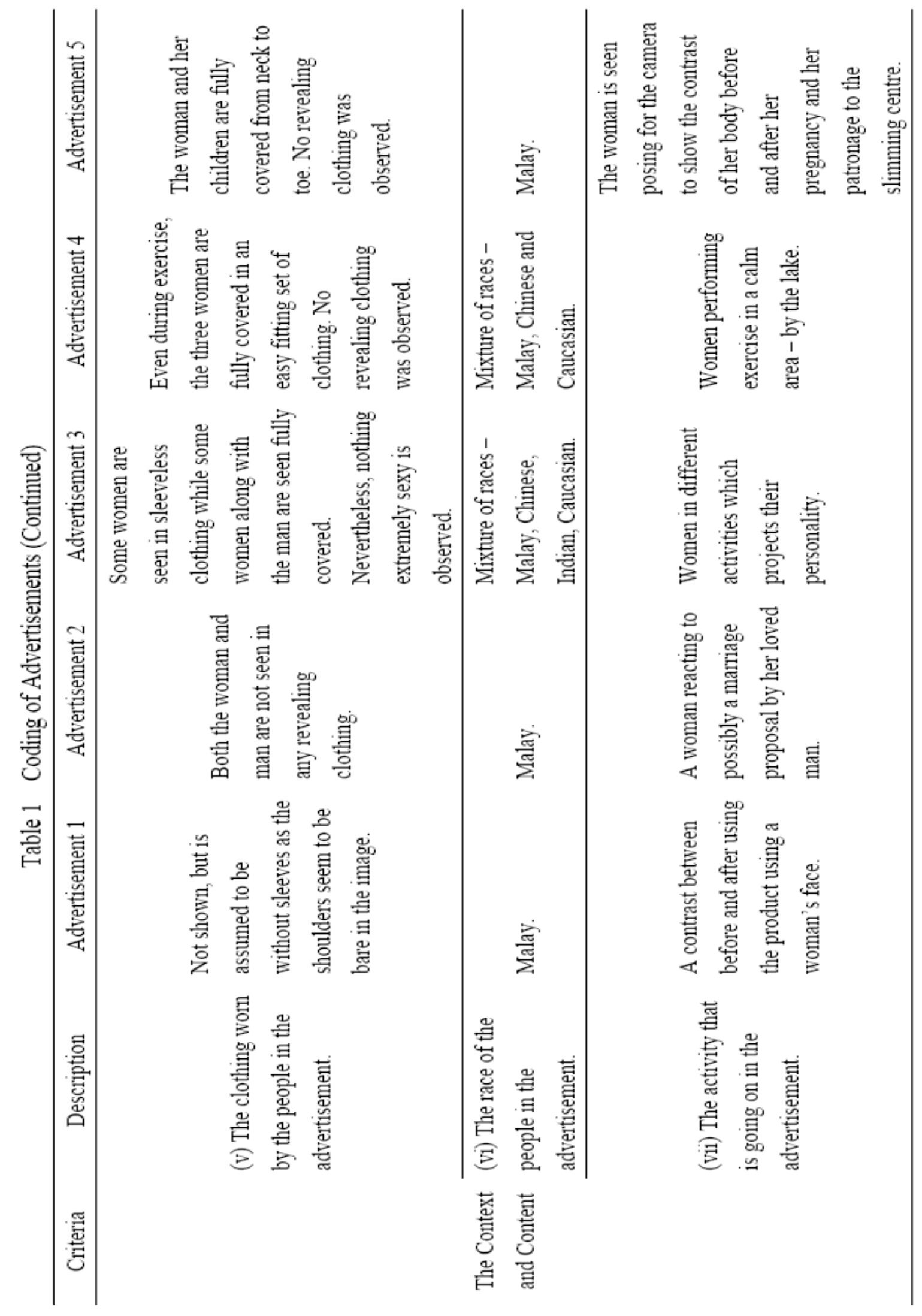




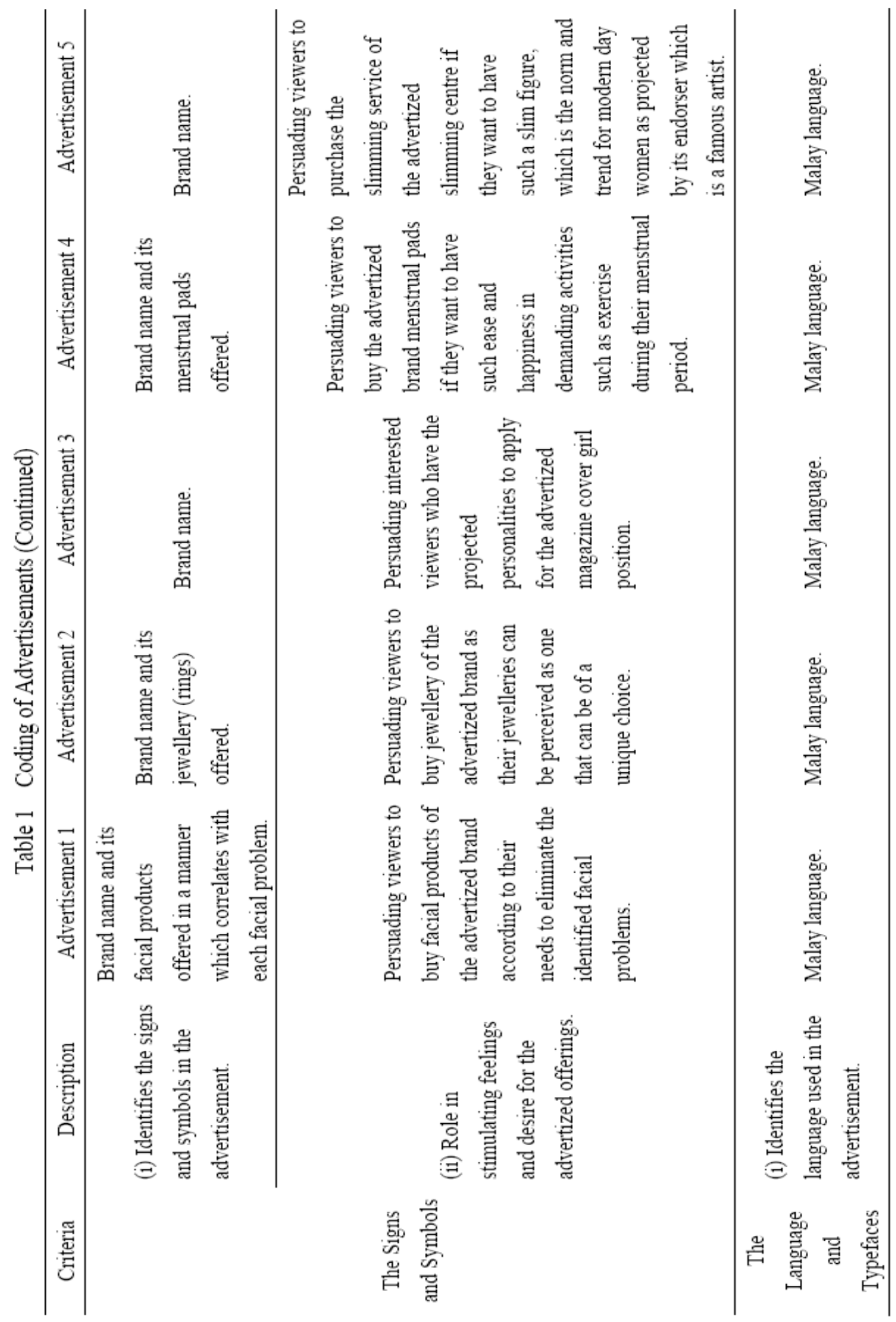




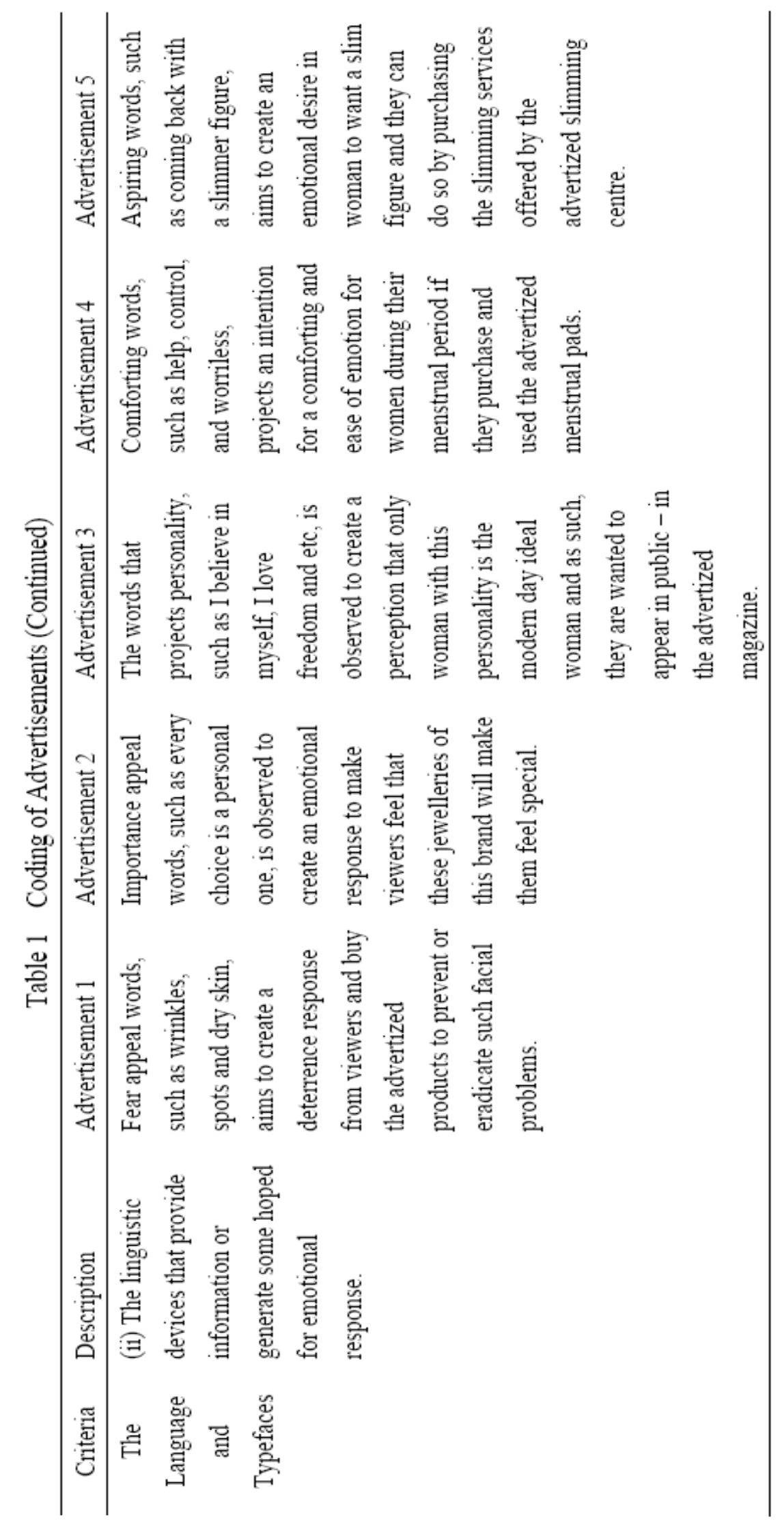




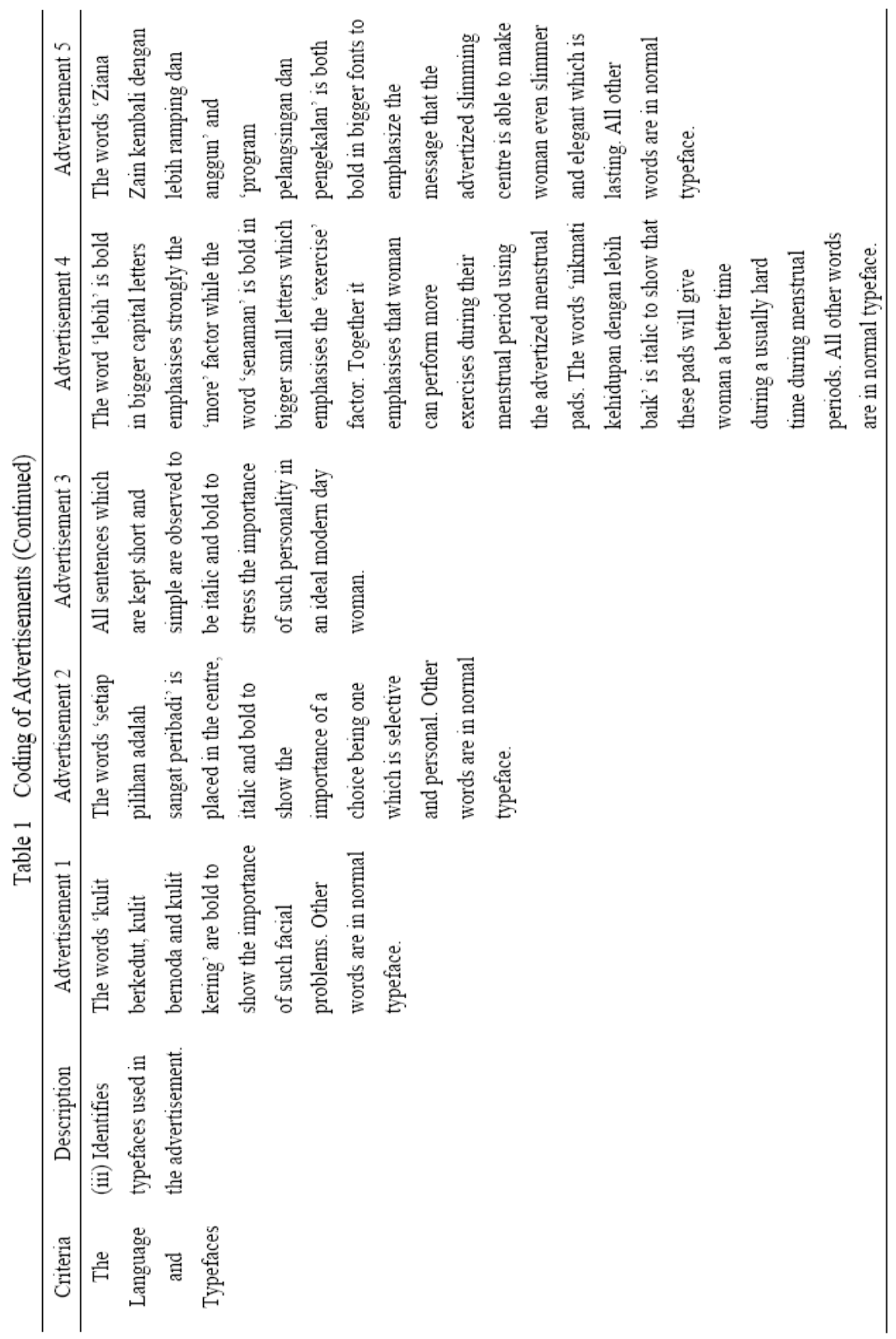




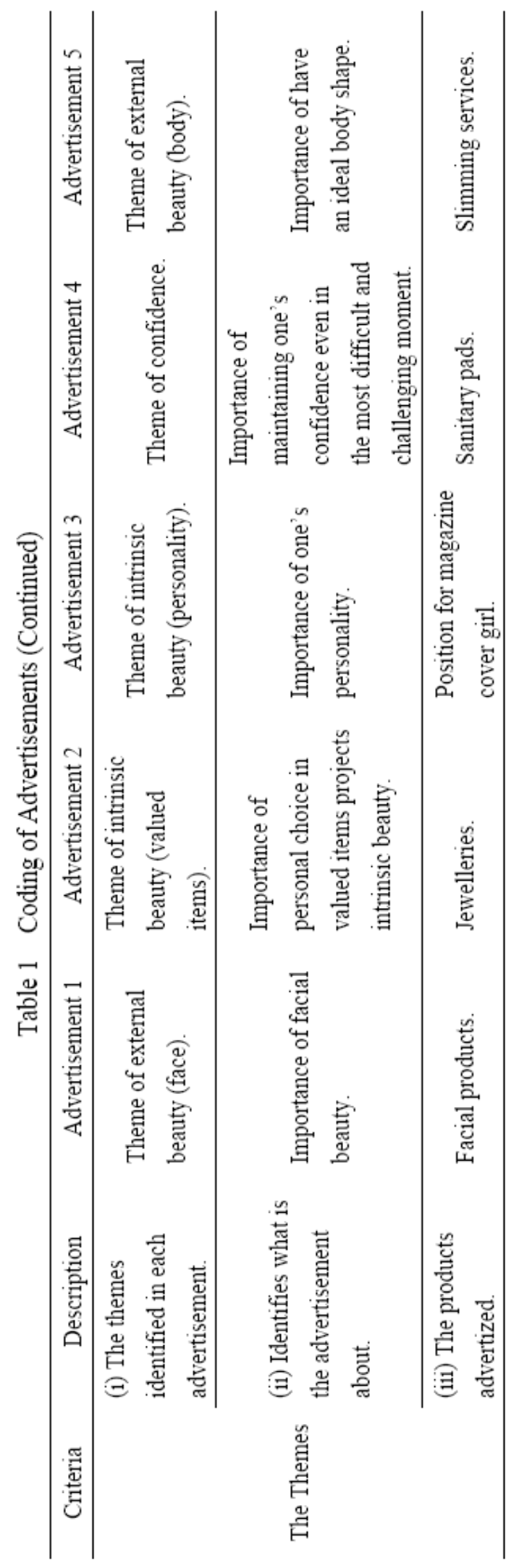




\section{DISCUSSION}

There are five Malay advertisements that are analyzed in this paper.

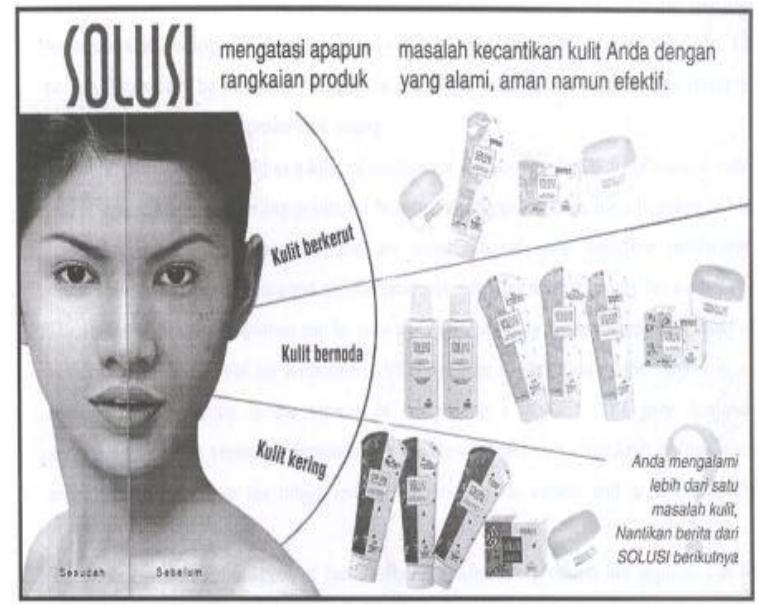

Advertisement 1

The first advertisement relates to the theme of external beauty (face) as it advertises women's cosmetics. It contains a photograph and a suggestive image, whereby wrinkled (kulit berkedut), spotted (kulit bernoda), and dry skin (kulit kering) are portrayed as a woman's problems. As such, it implies that a woman has to make these problems as her enemies that she needs to eliminate. This advertisement has capitalised on women's anxieties and fears of having these problems and presents its product as a solution to these problems. In particular, this advertisement implies that women will not be beautiful if they have wrinkled, spotted and dry skin. Besides that, it is observed that the hints of natural, safe and effective (alami, aman namun efektif) are strong selling points for beauty aids, such as the one advertized. It portrays that women have fears of using unsafe and ineffective chemical products. The advertiser takes advantage of these fears and instils a perception that what is natural is usually good, whereby its advertized product is able to offer a natural beauty to women (SOLUSI mengatasi apapun masalah kecantikan kulit anda dengan rangkaian product yang alami, aman namun efektif - SOLUSI overcomes any of your skin problem with its natural, safe, but effective products). On the other hand, the use of two different types of facial complexions, before and after using the product, can liken to the selling of magic as the change of the skin problems into a smooth, light and youthful skin is like magic. While most women are aware that magic is a mere illusion and it is not real, they become fascinated about these changes and become susceptible into believing that it is real. 
The second advertisement relates to the theme of intrinsic beauty, in terms of valued items, as it advertises women's jewelleries. Typically, the intrinsic meaning of items is able to bring out the personality and perception of women on these items, in this case, jewellery. An image of a young woman and a man is used to show the necessity of using Joensin jewellery. The words 'setiap pilihan adalah sangat peribadi' (every choice is a very private choice) presents two meanings. Firstly, the choice of giving the Joensin jewellery to young woman should be a private choice, in which it is personally chosen to be given to the woman. Secondly, the choice could also refer to the man's choice of the young woman as a special person who deserves a special gift. Relationally, the woman is portrayed with an astonished face and smile while looking at the piece of jewellery, which implies that the woman is very pleased to be given such a gift. Perhaps, she might not even imagine that she would get such a special gift. Nevertheless, such a woman deserves high fashion jewellery, such as the diamond wedding rings presented. Hence, being passive for a woman is gold as it is the kind of character that an ideal woman should display, especially in her relation to a man. Therefore, it can be said that women in Malay advertisements are typically portrayed as being passive, is in need of a man's special attention, should be viewed as something precious, and to be specially chosen by the man. Nevertheless, the presentation of such high fashion jewellery may not happened in the real world as not every man can afford such expensive gifts and thus, it would probably give women a degree of materialistic and unattainable hope for such a situation to occur.

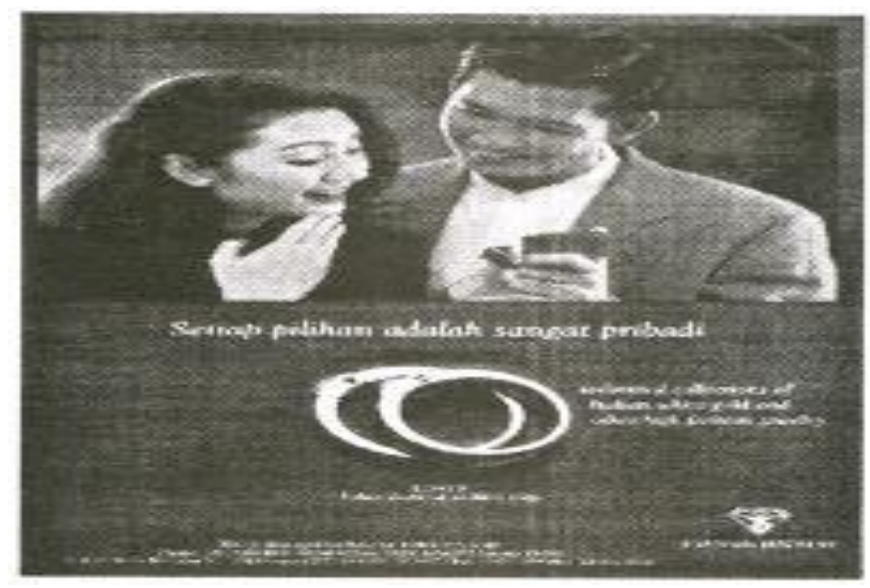

Advertisement 2 


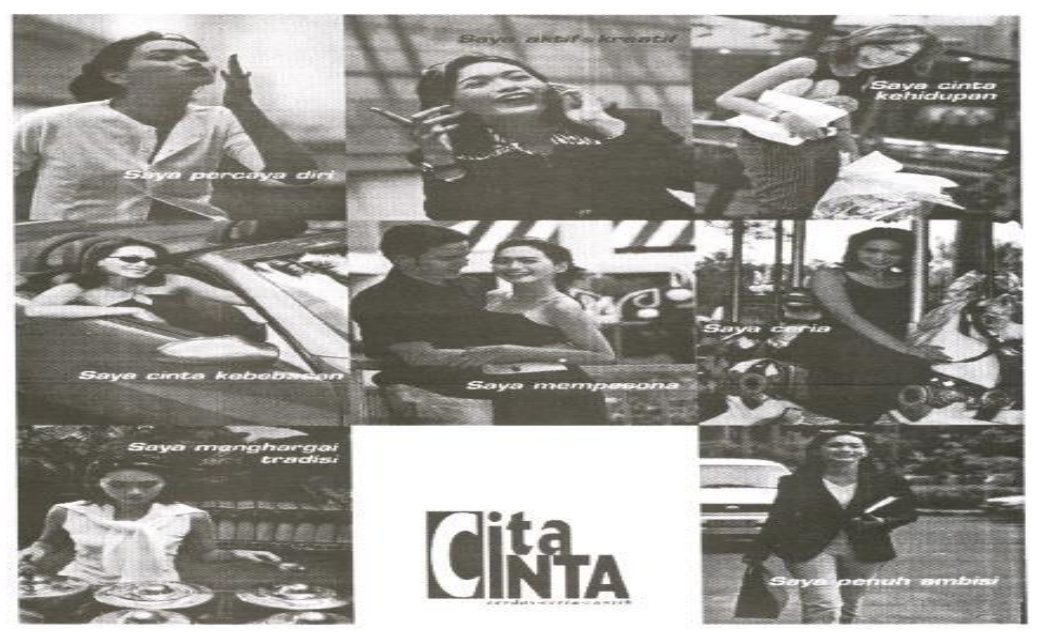

Advertisement 3

The third advertisement also relates to the theme of intrinsic beauty, but in terms of a woman's personality. The series of images show the kinds of women who can be considered as intelligent, cheerful and beautiful (cerdas, ceria, cantik). Typically, the eight pictures of young women with their actions and gestures depict their characteristics, whereby they are confident (percaya diri), are active and creative (aktif dan kreatif), love life (cinta kehidupan), love freedom (cinta kebebasan), are attractive (mempesona), appreciate tradition (menghargai tradisi) and are very ambitious (penuh ambisi). Apparently, the series of pictures in this advertisement are all images of young women. Thus, this gives an impression to viewers that in order to be intelligent, cheerful and beautiful, women have to look young, slim and sexy, rich, educated, and lovable. In particular, there is no place for an old, poor, fat, or uneducated woman to be included here. As such, these images in the Malay advertisement ought to shape the minds of its viewers with ideas of what is to be an ideal woman. Hence, it will no longer be the words that women will remember, but it will be the image of a woman driving a car, using a hand phone, walking with an uplifted face and carrying a case, relaxing, or being embraced by a man. Nevertheless, to achieve all these characteristics may be impossible by many women, typically to those who are not included in these images - such as old and fat women. 


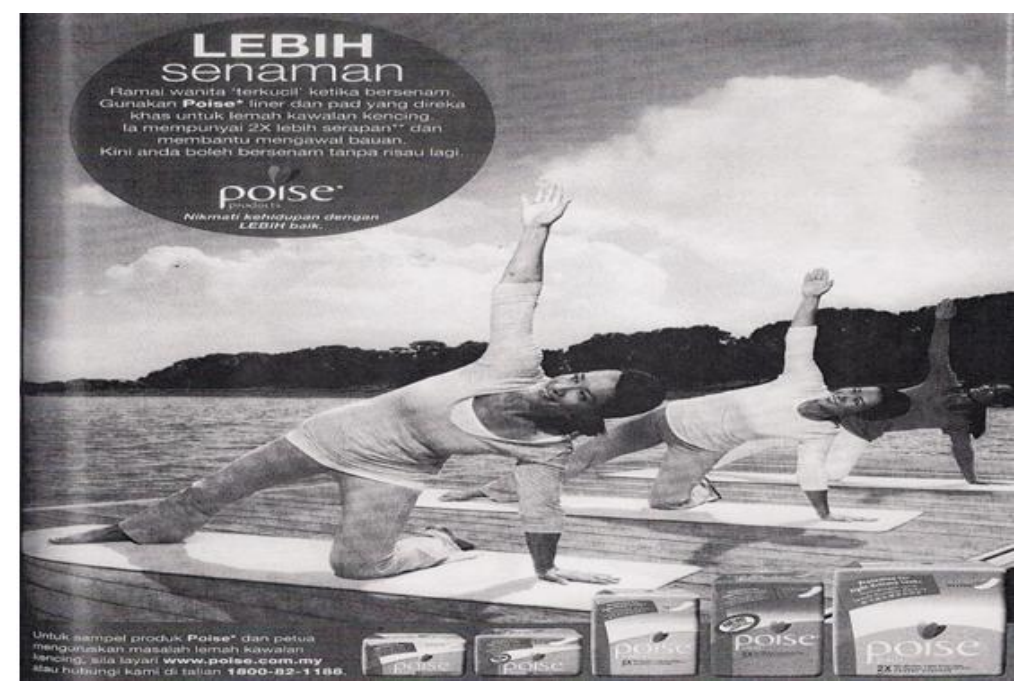

Advertisement 4

The fourth advertisement is an advertisement of sanitary pads, which relates to the theme of confidence. This advertisement contains scenery of three women who are experiencing their monthly menstrual period exercising by a lake at ease. Usually during this time of the month, women often stop many of their daily activities, including exercising, as they may feel uncomfortable and insecure of the smell and amount of blood discharged. Nevertheless, from this scene, it implies that modern women are portrayed with higher levels of confidence as these three women dare to go out and continue with their normal daily activities even during their menstrual period, whereby the use of the advertized range of Poise menstrual products is able to provide them with this security and thus, boosts their confidence. It is also noted that these women are wearing clothing of bright colours without any patterns, which further show their confidence in carrying out exercising activities. In addition, the advertisement implies that modern women are now more open on talking about this issue with others, as opposed to the conservativeness associated in the traditional times. Nevertheless, a sense of artificiality may be present as many women experience pain during their menstrual period and may not look as happy and calm as in the picture, even though the menstrual pad might be helpful to contain the smell and large amount of blood discharged. 


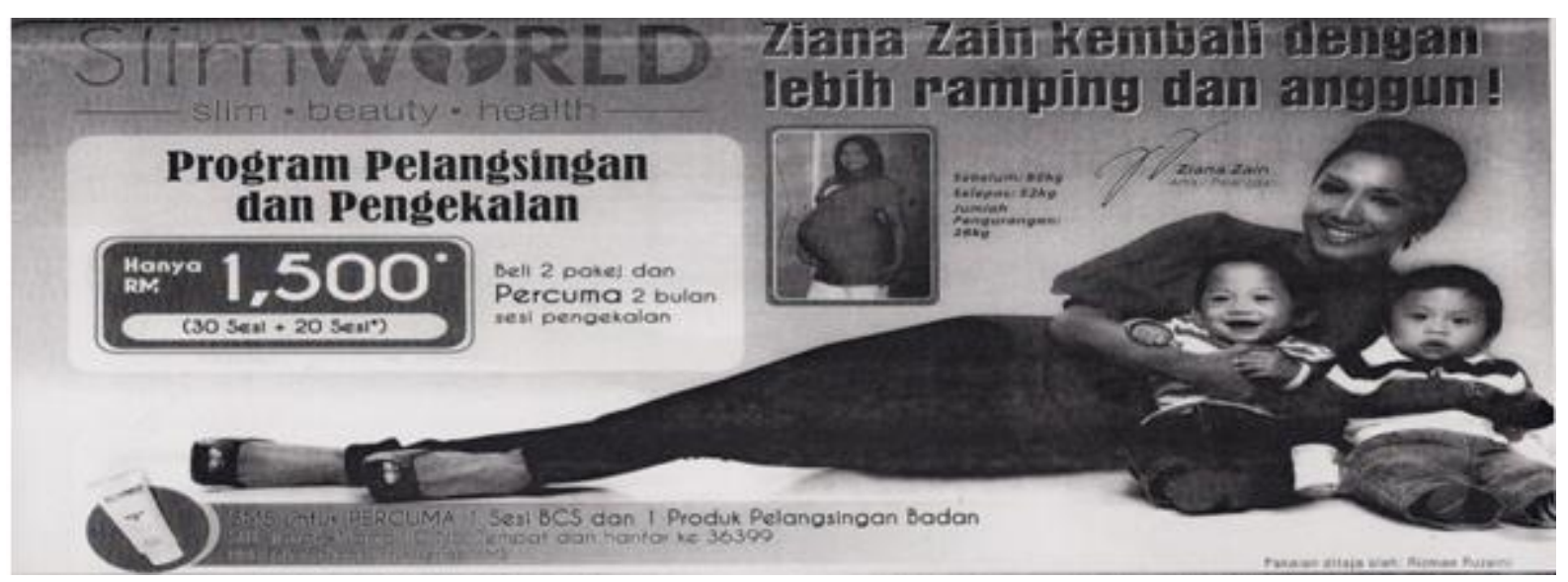

Advertisement 5

The fifth advertisement is an advertisement of a slimming centre, which relates to the theme of external beauty (body). Similar to the first advertisement, this advertisement uses two different images to show the effects of their slimming services - one shows a woman when she was pregnant and another shows the same women after she has given birth and undergone the slimming therapy provided by Slim World slimming centre. Ziana, the woman portrayed, is a famous Malaysian artist and was used as a celebrity and customer (artist, pelanggan) endorser in this advertisement, whereby the advertiser aims to show the trust of a famous fellow female to obtain a slim figure after using its therapies. Typically, it can be implied that whether a woman is young or old, a woman who has a slim figure will always be regarded as the ideal state of beauty. Even for women who have given birth, being slim is still very essential. The words that suggest that the Ziana Zain comes back with a slimmer and more beautiful body (kembali dengan lebih ramping dan anggun) further emphasize the importance of modern day women, typically mothers, to have a slim figure, even after giving birth. In addition, it is also observed that the advertisement states a loss of $28 \mathrm{~kg}$ after undergoing the slimming therapy, showing the effectiveness of its therapy. Nevertheless, a sense of artificiality may be observed whereby the picture of Ziana is shown when she was pregnant and her prior weight of $80 \mathrm{~kg}$ could be reflective of her with the baby in her womb. Thus, the effect of adding the baby's dimension and weight into a situation of Ziana being considered as 'fat' is rather artificial and seems to deceive its viewers. Furthermore, having such a slim figure after being pregnant once is already a very difficult mission to accomplish, let alone twice. 


\section{IMPLICATIONS}

Many scholars in the past have agreed to the notion that an imperative area of advertising that has an utmost need for analysis and change is the portrayal of women as the portrayal of such precious beings is argued to be continuously changing over time due to the rapid modernization and advancement of the human race and the surroundings they inhabit (Berger, 1999; Kuntjara, 2001; Ong and Seah, 2001). Nonetheless, despite the changes of time, many critics still argue that the roles that women play in the media are often demeaning (Coleman, 2010). This is supported by Kuntjara (2001) as it was found that over time, women, more often than not, are treated only as sexual objects, and used for display or as dummies who get excited about some brand, especially those of cleaning products. Frequently, they are not shown as active, but rather, as more passive figures who react to the initiatives of others, usually males (Berger, 1999). However, such observations which reside in the existing literature in the scholarship are often confined to advertisements in the American and European context (Ford, LaTour and Lundstrom, 1991; Rhode, 1995). While there may be scarce literature which looks at the portrayal of women in the Asian context, more often than not, it is a rather stereotyping thought of analysis which looks only at Asians who are of yellow skin - typically those who are Chinese, Japanese or Korean (Hung and Li, 2006; Siu and Au, 1997).

The current research, which looks at a race who is often overlooked in research considerations and implications when it comes to Asian studies - the Malays, have found observations that somewhat deviate from those annotations of women portrayal as sexual objects in the existing studies in the literature. In particular, it was observed through the sample of Malay advertisements in the current study that the external or the conventional beauty may not necessarily be depicted as a woman's only attribute. In occasions where women are depicted with the presence of men, it is observed that women have been portrayed as having the intrinsic beauty of being valued in terms of being something precious in the eyes of men. This depicts a contrasting insight in the portrayal of women in Malay advertisements as compared to existing studies in the American, European or other Asian contexts as women in the analyzed Malay advertisements were found to be rendered with more feeling of appreciation, rather than merely as an object that fulfil the desires of men. Indeed, the existence of such feelings in advertisements which is not only targeted to the Malay market, but also to the market of other races, is rather imperative as studies in the past have found that women in a multi-racial country, such as Malaysia, adore the feeling of being cared for and pampered, with a stressed importance of an overall feeling of being 
appreciated (Hassan and Kamaruddin, 2010). On the other hand, women presented in Malay advertisements have also been observed to possess intrinsic beauty for their personality and also having much confidence by having a young image with the characteristics of intelligent, cheerful, confident even during the worst period of times, and being beautiful naturally, unlike those found in the past scholarship which reports that a large portion of images of women were often portrayed with a dumb image, typically those who are blonde (Norton, 1999). The work of Nichols (2009) explained that the emergence of such modern image portrayals is mainly due to the fact that most men in the contemporary era are not just attracted to women solely based on their external beauty - both face and the body, but also, they tend to become deeply engrossed to those women who project a sense of intelligence and confidence and possess a cheerful and bubbly character. Indeed, such traits of attraction are argued by Heslop, Newman and Gauthier (2009) as becoming the goals that women of the modern era strive to become. Such a phenomenon is explain by Sumun (2011), who argues that all individuals are born naked and as they move on in life, they become actors simply because every day, most individuals, especially females, will put on some kind of costume when they walk out the front door to become the people that they are expected to be - predominantly, to fulfil the desires to meet the expectations of people who matter to them from both the same and opposite gender. Consequently, it can be implied that what amounts to the meaning of depicted images of women in advertisements accessible and circulated in a particular society can be argued as representing the desires of what that culture wants women in that particular society to be. Relationally, the difference between the portrayals found from Malay advertisements as compared to those advertisements studied in the past literature may be rationalized upon the influence of a culture which holds very much to their religious teachings with a strong respect and tolerance for the religious beliefs of others. Typically those cultures which are multi-racial, have a strong sense of diversity, and have at least one dominant belief which is more conservative and sensitive than others, such as the Malays in Malaysia, along with a wide coverage and span of provision for education in a society, as seen by the literacy rates in the research context, will undeniably lead to more respectable portrayal of images of women in their advertisements.

Nonetheless, with relation to conventional beauty, it was observed that there is existence of images of women in Malay advertisements being portrayed as a female who has no lines of wrinkles, is young, and has no scars, pores or blemishes. She is thin, generally tall and long-legged. Typically, all 'beautiful' women in the sample of 
Malay advertisements in this study conform to this norm. With relation to these observations of external beauty and the prior issues argued pertaining to intrinsic beauty and confidence, it can be further noted that such images project a strong sense of perfection. According to Siu and Au (1997), such perfect portrayal in media images are often results of fantasies and the creation of artificiality that establishes an impossible standard of physical and mental perfection for women. Rhode (1995) added that the true definition of beauty is that it is something that comes naturally without forcing oneself to spend money and time on cosmetics, personality training and other enhancements for or to create both external and internal beauty. The work of Harrison, Biljana and Cornwell (2001) further added that in cases where women are not able to conform to the ideal and impossible standard portrayed by media images, the majority of them are reported to go to a great length of effort to manipulate and change what is necessary as to what is required and portrayed in media images, typically their faces and bodies. In particular, it was noted that most women seem to have conditioned to view their faces as a mask and their body as an object (Frith, Shaw and Cheng, 2005). They are often in constant need of alteration, improvement and disguise. More often than not, such portrayal of media images with unnatural and artificial characteristics are often made to make a women feel dissatisfied with and ashamed of herself (Ong and Seah, 2001). As such, women are constantly exhorted to achieve this ideal, to feel ashamed and guilty if they fail, and to feel that their desirability and lovability are contingent upon such portrayed perfection. This is indeed true in a context where media with Malay advertisement content are circulated as a study by Kuntjara (2001) have found that more than half of young women who were exposed to Malay advertisements were dieting and three quarters felt they were over-weight. In her research, one respondent was recorded commenting that she did not expect guys to be handsome. Another added that while this is evident among the girls, guys expect girls to be perfect and beautiful, and skinny too! Such cruelty that beholds such a phenomenon is the fact that certain irresponsible advertisers are exploiting the use of special techniques to create 'reality effects' from the unreality, in which many women grow up thinking that they need to look like the women in the advertisements. For most women this is impossible; no matter how carefully they apply these products, they will never look like the pretty women depicted in the advertisements. Consequently, there is an underlying need for the government and non-profit organisations to strive towards informing and educating the public, typically women, in processing information that is seen in media images - that what is portrayed should not be taken too seriously as additional effects may have been 
created through advance visual technologies in an attempt by advertisers to shadow unreality. A concrete call for the government to look into measures to control the use of special techniques to create 'reality effects' from the unreality is also very much evident. To cushion the concern of undermining the advancement in visual designs, such special techniques is recommended to be limited to visuals that are not created to facilitate the selling of products or services of a company to consumers to prevent the exploitation of special visual effects in creating a need in consumers to buy the advertized offerings. Without the implementation of such control measures in an era with a rapid growth in the advancement in visual designs, society's fear of being unable to expect any truly realistic advertisements in the future may indeed become a reality - illusion will then be taken as reality instead.

\section{CONCLUSION}

In conclusion, it is observed that most advertisers use special and creative techniques to create 'reality effects' from the unreality. In particular, women in Malay advertisements are often portrayed: (i) in an ideal yet artificial state of perfect facial beauty, (ii) passive and as a precious object owned by men, (iii) young with the characteristics of intelligent, cheerful and beautiful, (iv) being absolutely slim in all conditions, and (v) having high confidence even in their worst periods of the month. While many women will internalize these stereotypes of what is considered to be an ideal woman, it is an impossible mission for most women as there is a sense of artificiality in most advertisements. Nonetheless, the results of this research cannot be generalized as a grounded theory for the portrayal of women in Malay advertisements as it only consists of one advertisement per theme. In order to improve the reliability and the generalizability of the results, future researches are recommended to be specifically devoted to look into a collection of Malay advertisements for only a specific theme. Other potential fruitful areas that future researches could naturally look at are comparisons between the perception of men and women on the portrayal of women in Malay advertisements as well as at the portrayal of both men and women cross-culturally and in other categories of media, such as Thai and Tamil advertisements in magazines, newspapers, television, radio and on the Internet. 


\section{REFERENCES}

Belova, O. (2006). Speaking for Themselves? Problematising the Production of Meaning in Visual Artefacts. Culture and Organization, 12(1), 37-49.

Berger, A. A. (1999). Sex as Symbol in Fashion Advertising and Analyzing Signs and Sign Systems. New York: Addison Wesley Longman.

Cash, T. F., and Diane, W. C. (1982). Women's Use of Cosmetics: Psychological Correlates and Consequences. International Journal of Cosmetic Science, 4(1), 16-24.

Chakraborty, R. (2009). Fitness Centres are Mushrooming, But Do They Get You Results? Retrieved May 29, 2011, from http://bangalore.citizenmatters.in/ articles/view/1645-fitness-centres-mushrooming/

Chan, M. K. (2010). Slimming Centers and Weight Loss Centers Review. Retrieved May 27, 2010, from http://www.slimmingcenter.org/

Chu, K. (2010). Extreme Dieting Spreads in Asia. Retrieved May 27, 2010, from http://content.usatoday.net/dist/custom/gci/InsidePage.aspx?cId=thejournalnews \&sParam $=3028234$. st

Coleman, B. (2010). Media Portrayal of Women: Female Stereotypes in the Media. Retrieved May 29, 2011, from http://brennacoleman.suite101.com/ media-portrayal-of-women-a189870/

Davis, C., Dionne, M., and Shuster, B. (2001). Physical and Psychological Correlates of Appearance Orientation. Personality and Individual Differences, 30(1), 21-30.

Denzin, N. K., and Lincoln, Y. S. (2005). The Sage Handbook of Qualitative Research ( $3^{\text {rd }}$ Ed.). Thousand Oaks, CA: Sage Publications.

Eriksson, P., and Kovalainen, A. (2008). Qualitative Methods in Business Research. Great Britain: Sage Publications.

Ferguson, J. H., Kreshel, P. J., and Tinkham, S. F. (1990). In the Pages of Ms.: Sex Role Portrayals of Women in Advertising. Journal of Advertising, 19(1), 40-51.

Ford, J. B., LaTour, M. S., and Lundstrom, W. J. (1991). Contemporary Women's Evaluation of Female Role Portrayals in Advertising. Journal of Consumer Marketing, 8(1), 15-28.

Frith, K., Shaw, P., and Cheng, H. (2005). The Construction of Beauty: A Cross-Cultural Analysis of Women's Magazine Advertising. Journal of Communication, 55(1), 56-70.

Gale, G. (1993). A Worldwide Overview of the Sanitary Protection Market. Retrieved May 27, 2010, from http://www.entrepreneur.com/tradejournals/article/ 13618636.html 
Ginsburg, R. (2009). Don't Tell, Dear. Journal of Material Culture, 1(3), 365-375.

Harrison, G., Biljana, J., and Cornwell, B. T. (2001). The Relationship of Advertising Model Attractiveness and Body Satisfaction to Intention to Purchase an Exercise Product. Asia Pacific Advances in Consumer Research, 4(1), 217-222.

Hassan, X. A., and Kamaruddin, K. K. (2010). What Do Malaysian Women Expect from Men in the $21^{\text {st }}$ Century? Journal of International Marketing Design, 2(1), 8-19.

Heath, C., and Hindmarsh, J. (2002). Analysing Interaction: Video, Ethnography and Situated Conduct. In T. May (Ed.), Qualitative Research in Action (pp. 99-121). London: Sage Publications.

Heslop, L., Newman, J., and Gauthier, S. (2009). Reactions of Women to the Portrayal of Women in Magazine Ads. Canadian Journal of Administrative Sciences, 26(2), 9-17.

Hooper-Greenhill, E. (2000). Museums and the Interpretation of Visual Culture. London: Routledge.

Hung, K., and Li, S. Y. (2006). Images of the Contemporary Woman in Advertising in China: A Content Analysis. Journal of International Consumer Marketing, 19(2), 7-28.

Ingham, H. (1995). The Portrayal of Women on Television. Retrieved May 29, 2011, from http://www.aber.ac.uk/media/Students/pth9601.html/

Johnston, J., and Taylor, J. (2008). Feminist Consumerism and Fat Activists: A Comparative Study of Grassroots Activism and the Dove Real Beauty Campaign. Journal of Women in Culture and Society, 33(4), 941-966.

Kay, G. (2005). Dying to be Beautiful: The Fight for Safe Cosmetics. Columbus: Ohio State University Press.

Kosher, D. W. (2006). Trendy Teen Jewellery Gaining Ground. Retrieved May 29, 2011, from http://www.diamondworld.net/contentview.aspx?item=2168/

Kuntjara, E. H. (2001). Beauty and the Beast: Images of Women in Advertisements. Journal Desain Komunikasi Visual, 3(2), 97-106.

Lindlof, T. R., and Taylor, B.C. (2002). Qualitative Communication Research Methods $\left(2^{\text {nd }} E d\right.$.). Thousand Oaks, CA: Sage Publications.

Marshall, C., and Rossman, G. B. (1998). Designing Qualitative Research. Thousand Oaks, CA: Sage Publications.

Moga, L. (2002). Meaning of Dreams about Jewellery. Retrieved May 27, 2010, from http://www.experiencefestival.com/meaning_of_dreams_about_jewellery 
Nichols, S. (2009). What Men Want in a Woman? 5 Types of Girl that Most Guys are Attracted to. Relationships, 15(3), 2-8.

Norton, C. (1999). Psychological Society Conference: Dumb Blonde Image is Still Alive and Well. Retrieved May 29, 2011, from http://www.independent.co.uk/ news/psychological-society-conference-dumb-blonde-image-is-still-alive-and-we 1l-1086243.html/

Ong, F. S., and Seah, S. (2001). Women's Perceptions toward the Portrayals of Women in Television Advertisements. Proceedings of the Asia Pacific Management Conference, Kuala Lumpur, 7, 477-490.

Red, M. (2010). Diamond Jewellery: The First Choice of Every Women. Retrieved May 27, 2010, from http://www.jewellerygem.com/2010/05/diamond-jewellerythe-first-choice-of-every-woman/

Rhode, D. L. (1995). Media Images: Feminist Issues. Signs, 20(3), 685-710.

Sengupta, S. (1992). Role Portrayals of Women in Magazine Advertisements: A Cross- Cultural Study. Media Asia, 19(3), 145-149.

Singh, V., Singh, S. P., Arora, M., and Sen, P. (2006). Knowledge Assessment Regarding Puberty and Menstruation among School Adolescent Girls of District Varanasi. Indian Journal Prevention Society of Medicine, 37(1/2), 9-14.

Siu, W. S., and Au, A. K. M. (1997). Women in Advertising: A Comparison of Television Advertisements in China and Singapore. Marketing Intelligence and Planning, 15(5), 235-243.

Stankiewicz, J. M., and Rosselli, F. (2008). Women as Sex Objects and Victims in Print Advertisements. Sex Roles, 58(7/8), 579-589.

Sumun, E. (2011). Life's a Drag. The Star. Retrieved June 8, 2011, from http://thestaronline.tv/v/7121

Venkat, M. (2009). Franchising in Wellness and Beauty Products. Retrieved May 27, 2010, from http://www.ado.alabama.gov/content/media/publications/trade/ mission/INDFranchisinginWellness\&BeautyProducts.pdf

Workman, J. E., and Johnson, K. K. P. (1991). The Role of Cosmetics in Impression Formation. Clothing and Textiles Research Journal, 10(1), 63-67. 